\title{
Correction to: Comparing benign laparoscopic and abdominal hysterectomy outcomes by time
}

\author{
Samantha L. Margulies ${ }^{1} \cdot$ Maria V. Vargas $^{2}$ (D) $\cdot$ Kathryn Denny $^{3} \cdot$ Andrew D. Sparks $^{4} \cdot$ Cherie Q. Marfori $^{2}$. \\ Gaby Moawad ${ }^{2} \cdot$ Richard L. Amdur ${ }^{4}$
}

Published online: 5 June 2019

(c) Springer Science+Business Media, LLC, part of Springer Nature 2019

\section{Correction to: Surgical Endoscopy https://doi.org/10.1007/s00464-019-06825-8}

The original article was updated to correct the author listing: the last five author names were reversed.

Publisher's Note Springer Nature remains neutral with regard to jurisdictional claims in published maps and institutional affiliations.

Samantha L. Margulies and Maria V. Vargas authors have equal contribution to this paper.

The original article can be found online at https://doi.org/10.1007/ s00464-019-06825-8.

Maria V. Vargas

mvvargas@mfa.gwu.edu

Samantha L. Margulies

smargulies.md@gmail.com

1 Department of Obstetrics, Gynecology and Reproductive Health Sciences, Yale School of Medicine, 310 Cedar Street FMB 307, New Haven, CT 06510, USA

2 Department of Obstetrics and Gynecology, Minimally Invasive Gynecologic Surgery, George Washington University School of Medicine and Health Sciences, 2150 Pennsylvania Avenue NW, Washington, DC 20037, USA

3 Department of Obstetrics and Gynecology, George Washington University School of Medicine and Health Sciences, Washington, DC, USA

4 Department of Surgery, George Washington University Medical Faculty Associates, Washington, DC, USA 